\title{
A produção do conhecimento sobre a relação entre educação e religião direcionadas aos povos indígenas no Brasil (1990-2018)
}

\author{
The production of knowledge about the relationship \\ between education and religion targeting indigenous \\ peoples in Brazil (1990-2018)
}

\author{
Cristiane Pereira Peres ${ }^{1}$ \\ Alessandra Cristina Furtado ${ }^{1}$
}

DOI: http://dx.doi.org/10.20435/tellus.vi43.664

\begin{abstract}
Resumo: O estudo compreende um mapeamento acerca da produção sobre a educação para os indígenas relacionada à religião, a partir da identificação de teses e dissertações do portal de periódicos da Coordenação de Aperfeiçoamento de Pessoal de Nível Superior (CAPES), da Biblioteca Digital de Teses e Dissertações (BDTD/IBICT) e dos trabalhos publicados nos Anais do Congresso Brasileiro de História da Educação (CBHE), no período entre 1990 e 2018. De caráter inventariante, a pesquisa buscou analisar as abordagens temáticas e metodológicas, assim como as fontes pesquisadas e os recortes temporais elegidos pelos pesquisadores. A investigação realizada permitiu identificar que as dissertações, as teses e os trabalhos completos privilegiaram como objeto de estudo, em sua maioria, a relação entre a educação e a religião, os missionários e a educação ministrada aos indígenas das diversas etnias, a política indigenista e sua relação com a educação escolar, e as pedagogias utilizadas pelos jesuítas na América portuguesa nos séculos XVI, XVII e XVIII. Desse modo, abordaram temáticas, até então, não escolhidas pelos pesquisadores dos cursos de pós-graduação. Assim, foi possível verificar que a educação para os indígenas e a educação escolar indígena já são temáticas de pesquisas privilegiadas pelos pesquisadores, contribuindo, dessa forma, com a escrita da história da educação no Brasil, com novos sujeitos, espaços e temporalidades. Contudo, constatou-se ainda que há necessidade da expansão dessas pesquisas quanto aos recortes temporais, geográficos e étnicos.
\end{abstract}

Palavras-chave: balanço bibliográfico; educação para os indígenas; religião; história da educação.

\footnotetext{
${ }^{1}$ Universidade Federal da Grande Dourados (UFGD), Dourados, Mato Grosso do Sul, Brasil.
} 


\begin{abstract}
The study comprises a mapping of the production on education for indigenous people related to religion, from the identification of theses and dissertations on the journal portal of the Coordination for the Improvement of Higher Education Personnel (CAPES), of the Digital Library of Theses and Dissertations (BDTD/IBICT) and from the works published in the Annals of the Brazilian Congress on the History of Education (CBHE), in the period between 1990 and 2018. In an inventive way, the research sought to analyze the thematic and methodological approaches, as well as the sources researched and the time frames chosen by the researchers. The investigation carried out made it possible to identify that the dissertations, theses, and completed works mostly privileged, as the object of study, the relationship between education and religion, the missionaries and the education given to the indigenous people of different ethnicities, the indigenous policy and its relationship with school education, and the pedagogies used by Jesuits in Portuguese America in the 16 th, 17th and 18th centuries. In this way, they approached themes, until then, not chosen by the researchers of the graduate courses. Thus, it was possible to verify that education for indigenous people and indigenous school education are already thematic of privileged research by researchers, thus contributing to the writing of the history of education in Brazil, with new subjects, spaces, and temporalities. However, it was also found that there is a need for the expansion of this research in terms of time, geography, and ethnicity.
\end{abstract}

Keywords: bibliographic balance; education for indigenous people; religion; history of education.

\title{
1 INTRODUÇÃo
}

Ao final da década de 1990, ocorreu uma expressiva preocupação no desenvolvimento de pesquisas que investigavam a história da educação escolar indígena, adentrando também no século XXI. Essa expansão de produções acerca da educação escolar, pautada na valorização da diversidade étnica e cultural, está relacionada à ampliação dos cursos de pós-graduação no Brasil a partir de 1980, especialmente na área das ciências humanas (BITTENCOURT, 2017).

Nesta perspectiva, este artigo objetiva mapear os estudos já realizados sobre a educação para os indígenas relacionada à religião entre os anos de 1990 e 2018. O recorte temporal inicial, em 1990, justifica-se pelo crescimento de pesquisas nos cursos de pós-graduação sobre a temática da educação escolar indígena, contribuindo, também, com iniciativas de investigações acerca da história da educação para os indígenas. Já a delimitação temporal final, 2018, corresponde ao levantamento realizado até este ano. 
Para alcançar o objetivo proposto neste artigo, foi necessário recorrer ao portal de periódico da Coordenação de Aperfeiçoamento de Pessoal de Nível Superior (CAPES), identificando teses e dissertações que versam sobre a temática; à Biblioteca Digital de Teses e Dissertações (BDTD/IBICT); aos Anais do Congresso Brasileiro de História da Educação (CBHE), realizado pela Sociedade Brasileira de História da Educação (SBHE), publicado desde o ano de 2000, com periodicidade bienal, com a seleção do eixo temático: "Gênero, etnia e educação escolar". Dos trabalhos identificados, observaram-se as abordagens temáticas e metodológicas, as fontes pesquisadas e os recortes temporais selecionados pelos pesquisadores. $\mathrm{Na}$ busca na base de dados da CAPES e do IBICT, foram selecionados os seguintes descritores: educação indígena; indígenas; ordens religiosas e ensino. O descritor, educação indígena foi escolhido por corresponder à forma pela qual os pesquisadores nomearam a temática até o início da educação escolar indígena; ensino, por buscar identificar os trabalhos que abordaram a educação ministrada aos indígenas; ordens religiosas, por compreender que a educação para os indígenas foi ministrada por pessoas ligadas às diversas ordens religiosas; e indígenas, pela recorrência da nomenclatura nos trabalhos.

Os resultados do mapeamento revelam o número de pesquisas que foram realizadas no Brasil sobre a educação direcionada aos povos indígenas. Mas é oportuno explicar que muitos trabalhos sobre a educação indígena e educação escolar indígena, por não configurarem o objetivo central deste estudo, não serão aqui apresentados. Deste modo, embora não seja o objetivo de identificação e análise deste artigo, cumpre destacar que a educação escolar indígena vem ocupando um expressivo espaço nas pesquisas acerca da educação no Brasil, investigando a formação de professores indígenas; o bilinguismo no processo de ensino e aprendizagem; a criança indígena; estudos sobre as escolas indígenas, e a educação intercultural e multicultural.

As temáticas abordadas corroboram com a importância e a necessidade de pesquisas que possuem como objetivo investigar a educação ministrada às diversas etnias indígenas ao longo da história de ocupação do Brasil, contribuindo com a escrita da história da educação para os indígenas e, também, da educação escolar indígena.

O texto está organizado em três seções: a primeira apresenta algumas reflexões sobre a educação direcionada aos povos indígenas; o balanço bibliográfico 
dos trabalhos identificados é apresentado na segunda seção, e, por fim, as considerações sobre a pesquisa realizada.

\section{EDUCAÇÃO PARA OS INDÍGENAS E EDUCAÇÃO ESCOLAR INDÍGENA: ALGU- MAS CONSIDERAÇÕES}

As primeiras experiências de uma educação não indígena, direcionada às diversas etnias, ocorreram com os jesuítas, membros da Companhia de Jesus ${ }^{2}$ em 1549, por meio da catequização. O projeto educacional jesuíta, que se manteve até 1759, buscou formar um novo perfil de homem indígena, voltado para o trabalho, assim como cristianizar os povos indígenas e torná-los sujeitos "civilizados", por meio do ensino pela fé.

Após a expulsão dos jesuítas de todas as colônias portuguesas no ano de 1759, as "aulas régias" (1759-1827) marcaram o segundo momento na história da educação no Brasil; de 1827 a 1890, houve as primeiras tentativas de organização de uma educação de responsabilidade do poder público, que era representado pelo governo imperial e pelos governos das províncias; o quarto momento é marcado pela criação das escolas primárias nos estados, entre os anos de 1890 a 1931; de 1931 a 1961, ocorreu a regulamentação das escolas superiores, secundárias e primárias; e, a partir de 1961 até o presente, adveio a unificação da regulamentação da educação nacional, em âmbito municipal, estadual e federal (SAVIANI, 2008).

No caso, a educação escolar indígena é um direito conquistado pelos povos indígenas desde a Constituição Federal de 1988 (BRASIL, 1988), sendo assegurada posteriormente com a Lei de Diretrizes e Bases da Educação Nacional (BRASIL, 1996).

Nesse sentido, ante o processo histórico de escolarização indígena iniciado por meio da evangelização, passando pela "civilização" e integração das etnias à sociedade não indígena, é notório que mesmo sendo garantido na legislação o respeito e a valorização das culturas dos povos indígenas, nos contatos com os não indígenas, esse direito foi violado, pautado em um ensino que negava as culturas indígenas, objetivando a incorporação da sua mão de obra na sociedade nacional.

Cabe evidenciar que a categoria de escola indígena passou a ser reconhecida legalmente somente em 1999, com o Parecer do Conselho Nacional de Educação

$\overline{{ }^{2} \text { Fundada em } 1534}$ por Inácio de Loyola e reconhecida por bula papal em 1540. 
n. 14/99 e da Resolução n. 03/99. O parecer enfatiza a necessidade da formação de professores indígenas, a produção de materiais didáticos específicos, o reconhecimento de programas e currículos específicos e a criação de condições de autonomia e autogestão nos projetos escolares (BRASIL, 1999).

Deste modo,

A finalidade do estado brasileiro, que procura aculturar e integrar os índios à sociedade envolvente por meio da escolarização, confronta-se, atualmente com os ideais de autodeterminação dos povos. Para os índios, a educação é essencialmente distinta daquela praticada desde os tempos coloniais, por missionários e representantes do governo. Os índios recorrem à educação escolar, hoje em dia, como instrumento conceituado de luta. (FERREIRA, 2001, p. 71).

A educação escolar indígena diferenciada ao longo dos anos vem sendo articulada e debatida em fóruns e assembleias pelos povos indígenas, principalmente, a partir da década de 1990, quando os povos indígenas passaram a assumir o debate sobre a implementação da política da educação escolar indígena e exigir sua efetivação e o respeito às diferenças, línguas e especificidades de cada povo indígena.

Nesse sentido, a educação escolar indígena diferenciada trabalha com a cultura da comunidade indígena, contribuindo com a permanência e a retomada dos costumes, crenças e tradições, reafirmando a identidade étnica.

Salientando que a cultura é dinâmica, portanto, a identidade é afirmada com base nas referências culturais presentes em um processo dinâmico, no qual o indivíduo passa por momentos de assimilação, aquisição e negação de outros símbolos culturais. Como afirma Candau (2009, p. 165), "[...] certamente cada cultura tem suas raízes, mas estas raízes são históricas e dinâmicas".

Assim, para que a educação escolar indígena diferenciada seja realmente efetivada nas escolas indígenas, é necessária a participação da comunidade no processo de escolarização. As lideranças indígenas e os anciãos possuem muitos conhecimentos tradicionais, que estão em suas memórias, necessitando ser repassados aos indígenas mais jovens.

Logo,

[...] a memória e a identidade exercem grande ligação, sendo a primeira o elemento constituinte do sentimento de identidade, e que essa identidade 
é um elo com a história passada e com a memória do grupo, onde a identidade é fortalecida através da memória, sendo que esta última mantém a coesão do grupo. (LE GOFF, 1992, p. 16).

Assim, a proposta de uma educação escolar indígena diferenciada e de qualidade é de extrema importância para as comunidades indígenas, pois, por meio de um currículo específico que contemple as tradições culturais indígenas, é possível contribuir com a afirmação da identidade via os ensinamentos formais e não formais, uma vez que "A escola indígena se caracteriza por ser comunitária, ou seja, espera-se que esteja articulada aos anseios de comunidade e a seus projetos de sustentabilidade territorial e cultural" (BRASIL, 2007, p. 21).

Isto posto, o ensino só é diferenciado se envolver os conhecimentos culturais da comunidade. Para os indígenas, a educação diferenciada não acontece somente na escola, mas no dia a dia, no conviver com a comunidade, nas histórias ouvidas e nas reuniões com as lideranças. Desse modo, para compreender a educação diferenciada para os indígenas, cabe recorrer ao conceito de cultura escolar. Para Julia (2001, p. 10-1), essa é definida como:

Um conjunto de normas que definem conhecimentos a ensinar e condutas a inculcar, e um conjunto de práticas que permitem a transmissão desses conhecimentos incorporação desses comportamentos; normas e práticas coordenadas a finalidades que podem variar segundo as épocas (finalidades religiosas, sociopolíticas ou simplesmente socialização). Normas e práticas não podem ser analisadas sem se levar em conta o corpo profissional dos agentes que são chamados a obedecer a essas 26 ordens e, portanto, a utilizar dispositivos pedagógicos encarregados de facilitar sua aplicação, a saber, os professores primários e aos demais professores.

Esse conceito de cultura escolar permite entender os elementos que modelam as instituições de ensino como a distribuição escolar do tempo e do espaço, as normas, a organização dos programas e as práticas educativas, o que torna significativo nesse estudo para a compreensão da organização dos programas e das práticas educativas que se fizeram e se fazem presentes entre os indígenas.

Desse modo, a cultura escolar, que foi sendo construída no processo de educação para os indígenas, ocorreu por meio da inculcação de novos costumes e novas práticas religiosas do não indígena. Mesmo assim, não se pode deixar de destacar que os indígenas também foram participantes ativos na construção da 
sua cultura escolar, fosse aderindo e/ou resistindo às novas práticas e aprendizados, assim como incorporando, aos programas, normas e práticas educativas das culturas indígenas.

\section{BALANÇO DAS PRODUÇÕES SOBRE A EDUCAÇÃO PARA OS INDÍGENAS: CAPES, BDTD E CBHE}

As pesquisas denominadas como estado do conhecimento são de caráter bibliográfico, permitindo identificar e compilar as produções científicas que versam sobre temas específicos, determinados pelo pesquisador. Deste modo, possibilitam

[...] discutir uma certa produção acadêmica [...] tentando responder que aspectos e dimensões vêm sendo destacados e privilegiados em diferentes épocas e lugares, de que formas e em que condições tem sido produzidas certas dissertações de mestrado, teses de doutorado, publicações em periódicos e comunicações em anais de congressos e de seminários. (FERREIRA, 2002, p. 257).

Após os procedimentos metodológicos adotados nessa pesquisa, seleção das bases de dados e descritores, foram identificados os seguintes números de produções que abordam a temática analisada: dois trabalhos publicados nos Anais do $\mathrm{CBHE}$; no IBICT, seis produções entre teses e dissertações, e nos periódicos da CAPES, foram identificados cinco trabalhos entre teses e dissertações que tiveram como objetivo de pesquisa investigar a educação para os indígenas. Seguem apresentados na Tabela 1:

Tabela 1 - Levantamento da produção da pesquisa (2000-2018)

20002002200420072008200920102012201520172018 Total

Trabalho completo 11

Dissertações

Teses

1

12

1

1 2

Fonte: elaboração das autoras, com base no banco de dados da CAPES, IBICT e Anais do CBHE, 2018.

A tabela permite perceber que o número de pesquisas sobre a educação para os indígenas passou a ser maior na última década, o que acaba por mostrar a relevância na produção científica e a necessidade de investigações que contribuam com a escrita da história da educação indígena. Certamente, pode-se 
dizer que a ampliação dos cursos de pós-graduação em educação e nas ciências humanas, assim como o expressivo aumento de pesquisas sobre a educação escolar indígena contribuíram com interesses de investigações acerca da educação para os indígenas.

Nesse sentido, na pesquisa realizada no portal de periódicos da CAPES, com a utilização dos descritores: educação indígena; ordens religiosas; ensino e indígenas, foi possível identificar o total de cinco trabalhos entre dissertações e teses que investigaram a educação para os indígenas no Brasil. Também foi possível notar que o maior número de trabalhos concentra-se entre dissertações (6), seguindo logo depois das teses (5). Além disso, foi possível constatar que o número de trabalhos completos divulgados nos Anais do CBHE ainda é bem reduzido. Cumpre inferir aqui que essa pouca produção nas edições do CBHE esteja associada ao fato dessa temática ainda integrar um número reduzido de objeto de estudos das investigações acadêmicas junto aos Programas de Pós-graduação tanto na área da Educação quanto nas Ciências Sociais e Humanas de modo geral. Para ilustrar essa abordagem, esses trabalhos seguem representados no Quadro 1.

Quadro 1 - Teses e dissertações sobre educação para os indígenas/CAPES (2004-2018)

\begin{tabular}{|c|c|c|c|c|c|}
\hline Autoria & Título & $\begin{array}{c}\text { Tipo de } \\
\text { Publicação }\end{array}$ & Ano & Instituição & Programa \\
\hline $\begin{array}{c}\text { CARVALHO, } \\
\text { Raquel Alves } \\
\text { de }\end{array}$ & $\begin{array}{l}\text { Os Missionários } \\
\text { Metodistas } \\
\text { na região de } \\
\text { Dourados e } \\
\text { a Educação } \\
\text { Indígena } \\
\text { na Missão } \\
\text { Evangélica Caiuá } \\
\text { (1928-1944) }\end{array}$ & Dissertação & 2004 & $\begin{array}{c}\text { Universidade } \\
\text { Metodista de } \\
\text { Piracicaba }\end{array}$ & Educação \\
\hline
\end{tabular}




\begin{tabular}{|c|c|c|c|c|c|}
\hline $\begin{array}{l}\text { LOURENÇO, } \\
\text { Renata }\end{array}$ & \begin{tabular}{|} 
O serviço de \\
proteção aos \\
índios e o \\
estabelecimento \\
de uma política \\
indigenista \\
republicana \\
junto aos índios \\
da reserva de \\
Dourados e \\
Panambizinho \\
na área da \\
educação escolar \\
(1929 a 1968)
\end{tabular} & Tese & 2007 & $\begin{array}{l}\text { Universidade } \\
\text { Estadual } \\
\text { Paulista Júlio } \\
\text { de Mesquita } \\
\text { Filho }\end{array}$ & História \\
\hline $\begin{array}{l}\text { NAKATA, } \\
\text { Cinthia }\end{array}$ & $\begin{array}{l}\text { Civilizar e educar: } \\
\text { o projeto escolar } \\
\text { indígena da } \\
\text { missão salesiana } \\
\text { entre os Bororo } \\
\text { do Mato Grosso }\end{array}$ & Dissertação & 2009 & $\begin{array}{l}\text { Universidade } \\
\text { de São Paulo }\end{array}$ & Antropologia \\
\hline $\begin{array}{c}\text { PAES, } \\
\text { Fernando } \\
\text { Luis Oliveira } \\
\text { Athayde }\end{array}$ & $\begin{array}{c}\text { Educar Mentes } \\
\text { e Salvar Almas: } \\
\text { Ação Missionária } \\
\text { Protestante na } \\
\text { Escolarização de } \\
\text { Indígenas No Sul } \\
\text { de Mato Grosso } \\
\text { (1928-1950) }\end{array}$ & Tese & 2015 & $\begin{array}{l}\text { Universidade } \\
\text { Federal de São } \\
\text { Carlos }\end{array}$ & Educação \\
\hline $\begin{array}{l}\text { FERNANDES, } \\
\text { Rosani de } \\
\text { Fatima }\end{array}$ & $\begin{array}{l}\text { "Na educação } \\
\text { continua do } \\
\text { mesmo jeito": } \\
\text { retomando } \\
\text { os fios da } \\
\text { história Tembé } \\
\text { Tenetehara de } \\
\text { Santa Maria do } \\
\text { Pará }\end{array}$ & Tese & 2017 & $\begin{array}{l}\text { Universidade } \\
\text { Federal do } \\
\text { Pará }\end{array}$ & Antropologia \\
\hline
\end{tabular}

Fonte: elaboração das autoras, com base no banco de dados da CAPES, 2018.

Esse quadro permite entrever que as pesquisas realizadas na forma de dissertações e teses foram efetivadas nos Programas de Pós-graduação da Educação, da Antropologia e da História, entre os anos de 2004 e 2017, e se concentraram, 
sobretudo, em universidades públicas e privadas situadas na região Sudeste do Brasil e, principalmente, localizadas no estado de São Paulo, como é o caso da Universidade Estadual Paulista (UNESP - Assis/SP), Universidade de São Paulo (USP - São Paulo/SP), Universidade Federal de São Carlos (UFSCAR - São Carlos/SP) e a Universidade Metodista de Piracicaba (UNIMEP - Piracicaba/SP). Além disso, fica bem evidenciado no quadro que apenas uma tese acerca da temática foi defendida fora do eixo da região Sudeste, no caso, junto ao Programa de Pós-Graduação em Antropologia na Universidade Federal do Pará, região Norte do Brasil.

Outro aspecto que fica bem evidente, no quadro sobre esses trabalhos que abordam temáticas com objetos de estudos ligados à educação indígena (como o processo de escolarização de diferentes etnias, como: dos Guarani, Kaiowá, Bororo e dos Tembé Tenetehara), é o fato de esses trabalhos terem sido realizados, em maior parte, tanto nos Programas de Pós-Graduação em Educação quanto de Antropologia, e apenas um trabalho na área de História.

Para um maior aprofundamento a respeito dessa abordagem, serão apresentados os trabalhos pesquisados nesse banco de dados da CAPES. Raquel Alves de Carvalho investigou a presença dos missionários metodistas em Mato Grosso, especificamente na região de Dourados, entre os anos de 1928 a 1946, compreendendo o envolvimento desses religiosos na educação dos indígenas Ñandeva e Kaiowá, por meio da interpretação das fontes documentais, analisando os discursos e imagens que foram veiculados sobre a região de Dourados e os indígenas (CARVALHO, 2004).

Com o intuito de compreender a instalação e ações da Missão Indígena Evangélica Caiuá na região de Dourados, a autora recorreu as seguintes fontes documentais: relatórios do Serviço de Proteção ao Índio; diários elaborados pelos missionários; atas; artigos; fotografias e imagens produzidas pelos missionários; ao jornal oficial da Igreja Metodista na época "Expositor Cristão", e a revista "A Voz Missionária". Nessa dissertação, a autora pode afirmar que a presença dos missionários metodistas, na Reserva Indígena de Dourados, teve como objetivo inculcar, nos indígenas, novas práticas culturais e de trabalho, por meio do ensino evangelizador.

Renata Lourenço, em sua tese de doutorado, teve como objetivo analisar a implementação da política indigenista via o Serviço de Proteção aos Índios (SPI) 
na educação escolar na Reserva de Dourados e da Aldeia Panambizinho, no período compreendido entre 1929 a 1968. Para o alcance do objetivo proposto, sua pesquisa pautou-se nos referenciais teórico-metodológicos da História Cultural, da História Social, da História Oral, da Antropologia e Etnografia. Nessa tese, a autora pesquisou sobre a temática nos documentos escritos presentes nos arquivos do Museu do Índio, no Rio de Janeiro, e realizou entrevistas com indígenas que frequentaram a escola entre as décadas de 1950 e 1960, possibilitando assim novas contribuições com a escrita da história sobre a educação no Brasil.

A autora Cinthia Nakata, em sua dissertação, a partir da produção de uma etnografia histórica, analisou a atuação pedagógica dos salesianos com os indígenas que habitavam o território mato-grossense na passagem do século XIX para o XX. A sua análise foi de caráter documental, com base nos relatos salesianos, o que possibilitou a autora desenvolver junto ao referencial teórico da Antropologia, da Sociologia e da História, a pesquisa realizada.

Em sua tese de doutorado, Fernando Luís Oliveira Athayde Paes abordou a ação missionária protestante na escolarização de indígenas da etnia Kaiowá-Guarani na Missão Evangélica Caiuá no antigo Sul de Mato Grosso (1928-1950). O autor analisou atas, relatório de conferências, jornais, fotos e outros documentos que contribuíram com a escrita da história da Missão Evangélica Caiuá. As fontes foram coletadas no Centro Cultural Martha Watts (Piracicaba, SP), no Museu do Índio (Rio de Janeiro), no Centro de Memória Metodista (São Bernardo do Campo, SP) e no Centro de Documentação Regional da Universidade Federal da Grande Dourados (Dourados, MS). O seu referencial teórico-metodológico foi baseado na História. Além disso, tomou como base os trabalhos sobre a história de Mato Grosso.

E, por fim, Rosani de Fátima Fernandes, em sua tese, discutiu sobre a saga dos Tembé Tenetehara das aldeias Jejue Areal que se autodeterminam de "Santa Maria do Pará", submetidos à catequese e à civilização pelos Freis Capuchinhos Lombardos da Missão do Norte, em parceira com o Governo do Pará no final do século XIX, com o objetivo de analisar os processos históricos de construção da educação escolar a que os indígenas foram submetidos. Para tal, recorreu às narrativas das histórias e memórias do povo Tembé Tenetehara de Santa Maria do Pará.

Assim, a ação missionária no processo de escolarização das diversas etnias indígenas; a relação da política indigenista com a educação escolar dos indígenas; 
e a educação para os indígenas foram objetos de investigação dos pesquisadores. Ao analisar a educação para os indígenas, organizada e ministrada pelas diversas ordens religiosas, cabe salientar que as temáticas da educação para os indígenas e da educação escolar indígena só passaram a ser possíveis de serem realizadas pela abertura e contribuição da nova historiografia educacional que passou a ser produzida no Brasil a partir de meados da década de 1980. Uma vez que "[...] as questões lançadas pela chamada Nova História Cultural vêm redesenhando as fronteiras e redefinindo os métodos e objetos da história da educação no Brasil" (CARVALHO, 2007, p. 116). Tal contribuição vem permitindo que investigadores de diferentes áreas do conhecimento escrevam a história da educação para os indígenas e da educação escolar indígena, com temáticas até então pouco privilegiadas pelos pesquisadores nos/dos cursos de pós-graduação. Dessa forma, a partir das contribuições da Nova História Cultural, novos objetos e métodos de pesquisa foram sendo selecionados pelos pesquisadores, contribuindo com o fazer e o escrever da História da Educação no Brasil, em especial, dos povos indígenas.

Assim, a partir das novas abordagens teórico-metodológicas da Nova História Cultural, foi possível reconfigurar a escrita da História da Educação, privilegiando sujeitos, espaços e práticas educacionais que até as últimas décadas do século XX não eram objetos de estudo dos pesquisadores.

Embora na consulta realizada na base de dados da Biblioteca Digital de Teses e Dissertações (BDTD/IBICT), alguns trabalhos se repetissem, foi possível inventariar seis trabalhos diferentes que se propuseram a estudar de certo modo a educação missionária direcionada as diversas etnias indígenas (Quadro 2).

Quadro 2 - Teses e dissertações inventariadas na base de dados da BDTD (2008-2018)

\begin{tabular}{|c|c|c|c|c|c|}
\hline Autoria & Título & $\begin{array}{c}\text { Tipo de } \\
\text { Publicação }\end{array}$ & Ano & Instituição & Programa \\
\hline $\begin{array}{c}\text { NOLASCO, } \\
\text { Patrícia } \\
\text { Carmello }\end{array}$ & $\begin{array}{c}\text { A educação jesuítica } \\
\text { no Brasil colonial } \\
\text { e a pedagogia de } \\
\text { Anchieta: catequese } \\
\text { e dominação }\end{array}$ & Dissertação & 2008 & $\begin{array}{c}\text { Universidade } \\
\text { Estadual de } \\
\text { Campinas }\end{array}$ & Educação \\
\hline
\end{tabular}




\begin{tabular}{|c|c|c|c|c|c|}
\hline $\begin{array}{l}\text { SOUSA, } \\
\text { Neimar } \\
\text { Machado } \\
\text { de }\end{array}$ & $\begin{array}{c}\text { A catequese colonial } \\
\text { jesuítica na região } \\
\text { do Itatim no século } \\
\text { XVII }\end{array}$ & Tese & 2009 & $\begin{array}{l}\text { Universidade } \\
\text { Federal de } \\
\text { São Carlos }\end{array}$ & Educação \\
\hline $\begin{array}{l}\text { FERREIRA, } \\
\text { Crisney } \\
\text { Tritapeppi }\end{array}$ & $\begin{array}{c}\text { A educação nos } \\
\text { aldeamentos } \\
\text { indígenas da } \\
\text { Capitania de São } \\
\text { Paulo no século XVIII } \\
\text { (entre a expulsão } \\
\text { jesuíta e as reformas } \\
\text { pombalinas) }\end{array}$ & Dissertação & 2009 & $\begin{array}{l}\text { Pontifícia } \\
\text { Universidade } \\
\text { Católica de } \\
\text { São Paulo }\end{array}$ & Educação \\
\hline $\begin{array}{l}\text { KASSAB, } \\
\text { Yara }\end{array}$ & $\begin{array}{c}\text { As estratégias } \\
\text { lúdicas nas ações } \\
\text { jesuíticas, nas terras } \\
\text { Brasílicas (1549- } \\
\text { 1597), "para a maior } \\
\text { glória de Deus" }\end{array}$ & Tese & 2010 & $\begin{array}{l}\text { Universidade } \\
\text { de São Paulo }\end{array}$ & $\begin{array}{l}\text { História } \\
\text { Social }\end{array}$ \\
\hline $\begin{array}{l}\text { DUARTE, } \\
\text { Marcelo } \\
\text { Felipe }\end{array}$ & $\begin{array}{l}\text { Teatro sombrio: o } \\
\text { demônio em cena } \\
\text { nos trópicos. O } \\
\text { papel do teatro } \\
\text { anchietano no } \\
\text { processo de } \\
\text { colonização da } \\
\text { América portuguesa } \\
\text { no século XVI }\end{array}$ & Dissertação & 2012 & $\begin{array}{l}\text { Universidade } \\
\text { do Estado } \\
\text { do Rio de } \\
\text { Janeiro }\end{array}$ & História \\
\hline $\begin{array}{l}\text { ANDRADE, } \\
\text { Leandro } \\
\text { Lente de }\end{array}$ & $\begin{array}{c}\text { Educação no } \\
\text { encontro cultural: } \\
\text { jesuítas e nativos na } \\
\text { América portuguesa } \\
\text { do século XVI }\end{array}$ & Dissertação & 2018 & $\begin{array}{c}\text { Universidade } \\
\text { Federal de } \\
\text { Alfenas }\end{array}$ & Educação \\
\hline
\end{tabular}

Fonte: elaboração das autoras, com base no banco de dados da BDTD/IBICT, 2018.

Das pesquisas identificadas na base de dados do IBICT, todas foram realizadas em universidades da região Sudeste, o que permite reafirmar a permanência de pesquisas acerca dessa temática sendo realizadas nos programas de pós-graduação das universidades públicas e privadas situadas nesta região, localizadas em sua maioria no estado de São Paulo, como na Universidade Estadual de Campinas (UNICAMP - Campinas/SP), Universidade Federal de São Carlos 
(UFSCAR - São Carlos/SP), Universidade de São Paulo (USP - São Paulo/SP) e a Pontifícia Universidade Católica de São Paulo (PUC - São Paulo/SP). Apenas dois trabalhos (dissertação) foram defendidos em universidades fora de São Paulo, um na Universidade do Estado do Rio de Janeiro (UERJ - Rio de Janeiro/RJ), e o outro na Universidade Federal de Alfenas (UNIFAL - Minas Gerais/MG). Do total de seis trabalhos, quatro foram desenvolvidos em programas de Educação, apresentando assim o crescimento de pesquisas na área da educação. Os outros dois foram defendidos nos programas de História e História Social.

Cumpre ainda mencionar aqui que as pesquisas sobre a educação ministrada aos diversos povos indígenas pelos missionários passaram a apresentar maiores interesses de investigação a partir do ano de 2008, e tiveram maior concentração nos Programas de Pós-graduação em Educação. Certamente, pode-se dizer que as investigações sobre a temática, a partir deste período, podem estar relacionadas à Lei n. 11.645/2008, que tornou obrigatório o ensino sobre a História e a Cultura Indígena na educação básica.

Assim, para um maior conhecimento dessa temática, serão apresentados os trabalhos identificados nesse banco de dados da BDTD/IBICT. A dissertação desenvolvida por Patrícia Carmello Nolasco analisou as ações de catequização dos jesuítas na colônia portuguesa no século XVI, praticadas via algumas obras do Padre José de Anchieta, afirmando que a educação no Brasil teve início com a catequese. Para o alcance do objetivo elencado pela pesquisadora, foram utilizadas as obras do Padre Anchieta como fonte de pesquisa.

A catequização também foi objeto de estudo da tese de Neimar Machado de Sousa, que investigou os princípios fundamentais da educação jesuítica colonial entre os Itatim no século XVII. Para tal análise, recorreu às fontes manuscritas da Coleção de Angelis, e ao referencial da História Colonial e da História Cultural.

Já Crisney Tritapeppi Ferreira, em sua dissertação de mestrado, direcionou a sua pesquisa para a educação dos indígenas nos aldeamentos da capitania de São Paulo. Para tanto, a partir do método indiciário de Ginzburg, analisou a educação ministrada aos indígenas nos aldeamentos em estudo, tomando como fontes as cartas jesuíticas e a história dos aldeamentos e da atividade missionária no Brasil, construída a partir dos relatos dos colonos, administradores, religiosos, portugueses e populações indígenas, que foram os documentos analisados no desenvolvimento da pesquisa. 
Em sua tese de doutorado, Yara Kassab analisou as estratégias lúdicas utilizadas pelos primeiros jesuítas na América portuguesa entre 1549 a 1579 para educar e catequizar os indígenas. Para tal análise, contou com os documentos elaborados por Inácio de Loyola, analisando 219 cartas contidas na obra Cartas dos Primeiros Jesuítas do Brasil de Serafim Leite (1956-1958), que alicerçaram a pedagogia jesuítica.

O lúdico utilizado nas práticas de catequização dos indígenas, também foi objeto de estudo da dissertação de mestrado de Marcelo Felipe Duarte, que pesquisou sobre o "Teatro sombrio: o demônio em cena nos trópicos. O papel do teatro anchietano no processo de colonização da América portuguesa no século XVI". Para investigar sobre a pedagogia do medo utilizada pela Companhia de Jesus nesse período para com os indígenas, teve como base o Auto de São Lourenço, escrito pelo padre José de Anchieta.

E, por fim, Leandro Lente de Andrade, em sua dissertação de mestrado, investigou a educação no encontro cultural entre os jesuítas e os indígenas na América portuguesa no século XVI, analisando as cartas jesuíticas. Teve como referencial teórico a História Cultural a partir das discussões de Michel de Certeau e Roger Chartier.

Entre os trabalhos apresentados no Quadro 2, foi possível observar que os documentos de fundos religiosos são "privilegiados" nas pesquisas, como as cartas jesuíticas, o Auto de São Lourenço e as cartas dos primeiros jesuítas do Brasil de Serafim Leite (1956-1958). As pesquisas que se propõem investigar a educação para os indígenas em períodos recuados como os séculos XVI, XVII e XVIII possuem, como fontes, os documentos escritos pelos jesuítas e colonizadores. Isso torna necessário problematizar a educação e a relação com os indígenas, entrecruzando as fontes, questionando e contextualizando os documentos com a proposta de catequização. Observando, também, como os jesuítas e os colonizadores registravam a reação dos indígenas ante as propostas de ensino, pois, a partir desses registros, é possível perceber como os indígenas resistiram, aderiram e assimilaram a educação elaborada pelos não indígenas, construindo assim a sua própria história.

Além dos trabalhos identificados na base de dados da CAPES e do IBICT, foi possível encontrar mais dois trabalhos que foram apresentados no Congresso Brasileiro de História da Educação, que também pesquisaram temática ligada à escolarização dos indígenas (Quadro 3). 
Quadro 3 - Quantitativo de trabalhos sobre educação indígena nos CBHEs $(2000-2017)^{3}$

\begin{tabular}{|c|c|c|c|c|c|}
\hline Autoria & Título & $\begin{array}{c}\text { Tipo de } \\
\text { Publicação }\end{array}$ & Ano & Instituição & Programa \\
\hline $\begin{array}{c}\text { AZCONA, Laura; } \\
\text { BEIERBACH, } \\
\text { Evangelina; } \\
\text { GONZALEZ, } \\
\text { Valeria; PICCO, } \\
\text { Estela }\end{array}$ & $\begin{array}{l}\text { La educación como } \\
\text { encuentro entre } \\
\text { dos culturas en las } \\
\text { misiones jesuíticas: } \\
\text { ficciones Y utopías }\end{array}$ & $\begin{array}{l}\text { Trabalho } \\
\text { completo }\end{array}$ & 2000 & $\begin{array}{c}\text { Universidad } \\
\text { Nacional de La } \\
\text { Pampa }\end{array}$ & Educação \\
\hline $\begin{array}{c}\text { CARVALHO, } \\
\text { Raquel Alves de }\end{array}$ & $\begin{array}{l}\text { A presença dos } \\
\text { missionários } \\
\text { metodistas e } \\
\text { presbiterianos na } \\
\text { região de Dourados } \\
\text { e a Educação } \\
\text { indígena na Missão } \\
\text { Evangélica Caiuá } \\
\text { (1928- 1950) }\end{array}$ & $\begin{array}{l}\text { Trabalho } \\
\text { completo }\end{array}$ & 2002 & $\begin{array}{c}\text { Universidade } \\
\text { Metodista de } \\
\text { Piracicaba }\end{array}$ & Educação \\
\hline
\end{tabular}

Fonte: elaboração pelas autoras, com base nos dados dos CBHEs, 2018.

Este quadro permite identificar que foram localizados apenas dois trabalhos publicados nos Anais do Congresso Brasileiro de História da Educação, entre os anos de 2000 a 2017, ambos pertencentes à Educação. Sendo um trabalho de autores da Argentina e o outro desenvolvido em uma Universidade do Sudeste, já apresentado acima como resultado final de dissertação de mestrado defendida por Raquel Alves de Carvalho.

O trabalho "La educación como encuentro entre dos culturas en las misiones jesuíticas: ficciones y utopías", apresentado no ano de 2000 no CBHE, é de autoria de Laura Azcona; Evangelina Beierbach; Valeria Gonzalez; Estela Picco e foi desenvolvido na Universidad Nacional De La Pampa em General Pico/Argentina. A pesquisa abordou a educação no encontro entre duas culturas nas missões jesuítas, enfatizando a imposição da cultura não indígena para as diversas etnias na América portuguesa, o que ocasionou os mais diversos conflitos.

3 A pesquisa realizada nos Anais do Congresso Brasileiro de História da Educação teve como recorte final o ano de 2017, em razão de o Congresso ser bienal, assim, não ocorreu o evento no ano de 2018, sendo realizado no ano de 2019. 
O segundo trabalho também analisou a ação missionária na educação dos indígenas, por meio de práticas religiosas de "civilização", integração e assimilação. A pesquisa documental do trabalho "A presença dos missionários metodistas e presbiterianos na região de Dourados e a Educação indígena na Missão Evangélica Caiuá (1928-1950)" foi desenvolvida com a análise dos relatórios do Serviço de Proteção ao Índio, das fotografias e imagens produzidas pelos missionários, do jornal oficial da Igreja Metodista na época, "Expositor Cristão", e da revista "A Voz Missionária".

Os trabalhos apresentam que as investigações acerca da educação para os indígenas estão sendo desenvolvidas no Brasil e em outros países, como na Argentina, pesquisando sobre as diversas etnias e as mais variadas práticas pedagógicas impostas pelos missionários.

Deste modo, segundo Le Goff (2003, p. 19), "Há uma historicidade da história que implica o movimento que liga uma prática interpretativa a uma práxis social". Assim, as abordagens sobre a educação para os indígenas, apresentadas nos trabalhos de dissertações e teses, contribuem com a escrita da História da Educação no Brasil, em particular, da educação para os indígenas e da educação escolar indígena, sobretudo ao analisar a relação entre a educação e a religião no processo educacional elaborado pelas ordens religiosas para os indígenas.

\section{CONSIDERAÇÕES FINAIS}

O mapeamento da produção sobre a educação para os indígenas entre os anos de 1990 e 2018 no portal de periódicos da CAPES, na Biblioteca Digital de Teses e Dissertações (BDTD/IBICT) e nos Anais do Congresso Brasileiro de História da Educação (CBHE) permitiu identificar que as dissertações, teses e os trabalhos completos privilegiaram como objeto de pesquisa, em sua maioria, a relação entre a educação e a religião; os missionários e a educação ministrada aos indígenas de diversas etnias; a política indigenista e sua relação com a educação escolar indígena; e as pedagogias utilizadas pelos jesuítas na América portuguesa nos séculos XVI, XVII e XVIII. Desse modo, pode-se dizer que acabaram por abordar temáticas, até então, não privilegiadas pelos pesquisadores dos cursos de pós-graduação.

O estudo de caráter inventariante, como é o caso desse mapeamento, possibilitou, ainda, verificar que a concentração da produção dos trabalhos se deu 
na área da Educação, entre dissertações, teses e trabalhos completos, pois oito trabalhos foram realizados nessa área do conhecimento. Outros dois trabalhos foram na área da História, dois na Antropologia e um trabalho na área da História Social. O expressivo número na área da/na Educação indica a preocupação dos pesquisadores em escrever a História da Educação para os indígenas, contribuindo com a escrita da História da Educação no Brasil, além de mostrar um reconhecimento e a valorização das diversas etnias indígenas de diversas regiões do Brasil.

Por meio das pesquisas inventariadas, é possível perceber que os recortes temporais foram delimitados entre os séculos XVI, XVII e XVIII, demonstrando assim a necessidade de pesquisas que abordem os séculos XIX e XX, quanto à educação ministrada aos indígenas pelas diversas ordens religiosas. A escassez ainda de trabalhos envolvendo a temática da educação para os indígenas nos períodos que abrangem os séculos XIX e XX pode ser considerada como uma lacuna nas produções do portal de periódicos da CAPES, na Biblioteca Digital de Teses e Dissertações (BDTD/IBICT) e nos Anais do Congresso Brasileiro de História da Educação ( $\mathrm{CBHE}$ ); no entanto, também indica uma perspectiva de pesquisa que contribuirá intensamente para o enriquecimento da História da Educação.

Contudo, é notório que a educação para os indígenas e a educação escolar indígena já são temáticas de pesquisas privilegiadas pelos pesquisadores em História da Educação; assim, a análise dos trabalhos mapeados neste artigo acaba por sinalizar para o fato de que, na História da Educação Brasileira, essa temática se configura como um espaço de expansão das pesquisas nessa área do conhecimento. Porém, ainda há a necessidade da disseminação dessas pesquisas sobre essa temática quanto aos recortes temporais, geográficos e étnicos.

\section{REFERÊNCIAS}

BITTENCOURT, Circe Fernandes. História da educação indígena no Brasil: percursos de pesquisas. Revista Anuario de Historia de la Educación, Buenos Aires, v. 18, n. 2, 2017. p. 100-13.

BRASIL. Ministério da Educação. Educação escolar indígena: diversidade sociocultural indígena ressignificando a escola. Brasília-DF, 2007.

BRASIL. Parecer CNE/CEB n. 14/99, de 14 de setembro de 1999. Sobre as diretrizes curriculares nacionais da educação escolar indígena. Diário Oficial da União, Brasília-DF, 
A produção do conhecimento sobre a relação entre educação e religião direcionadas aos povos indígenas no Brasil (1990-2018)

19 de outubro de 1999. Disponível em: http://portal.mec.gov.br/cne/arquivos/pdf/1999/ pceb014_99.pdf. Acesso em: 26 out. 2018.

BRASIL. Lei n. 9.394, de 20 de dezembro de 1996. Lei de Diretrizes e Bases da Educação. Brasília-DF, 1996.

BRASIL. Assembleia Nacional Constituinte. Constituição da República Federativa do Brasil. Brasília-DF, 1988.

CANDAU, Vera Maria. Direitos humanos, educação e interculturalidade: as tensões entre igualdade e diferença. In: CANDAU, Vera Maria (Org.). Educação intercultural na América Latina: entre concepções, tensões e propostas. Rio de Janeiro: 7 Letras, 2009.

CARVALHO, Marta Maria Chagas. Manuais de pedagogia, materialidade do impresso e circulação de modelos pedagógicos no Brasil. Revista Colombiana de Educación, Bogotá, v. 20, n. 52, p. 114-35, 2007.

CARVALHO, Raquel Alves. Os missionários metodistas na região de Dourados e a educação indígena na Missão Evangélica Caiuá (1928-1944). 2004. 133 f. Dissertação (Mestrado em Educação) - Universidade Metodista de Piracicaba, São Paulo, SP, 2004.

FERREIRA, Norma Sandra de A. As pesquisas denominadas "estado da arte". Educação \& Sociedade, São Paulo, v. 23, n. 79, p. 257-72, ago. 2002.

FERREIRA, Mariana Kawall Leal. A educação escolar indígena: um diagnóstico crítico da situação no Brasil. In: LOPES DA SILVA, Aracy; FERREIRA, Mariana Kawall Leal. (Org.). Antropologia, história e educação: a questão indígena e a escola. São Paulo: Global, 2001.

JULIA, Dominique. Cultura escolar como objeto histórico. Revista Brasileira de História da Educação, São Paulo, v. 20, n. 1, p. 63-82, 2001.

LE GOFF, Jacques. História e memória. Campinas: UNICAMP, 1992.

LE GOFF, Jacques. Memória. In: LE GOFF, Jacques. História e memória. 5. ed. Campinas: UNICAMP, 2003.

SAVIANI, Dermeval. História da história da educação no Brasil: um balanço prévio e necessário. Eccos Revista Científica, São Paulo, v. 10, n. especial, p. 147-67, 2008. 


\section{Sobre as autoras:}

Cristiane Pereira Peres: Doutoranda em Educação pela Universidade Federal da Grande Dourados (UFGD). Mestre e graduada em História pela Universidade Federal da Grande UFGD. E-mail:cristiapereira@hotmail.com,ORCID:http://orcid.org/0000-0002-5906-2834

Alessandra Cristina Furtado: Doutora em Educação pela Universidade de São Paulo (USP). Mestre e graduada em História pela Faculdade de História, Direito e Serviço Social pela Universidade Estadual Paulista (UNESP/Franca). Docente na Faculdade de Educação e no Programa de Pós-Graduação em Educação stricto sensu na Universidade Federal da Grande Dourados (UFGD). Líder do Grupo de Estudos e Pesquisa em História da Educação, Memória e Sociedade na UFGD. E-mail: alessandra_furtad@yahoo.com.br, ORCID: http://orcid.org/0000-0002-6084-2299

Recebido em: 12/12/2019.

Aprovado para publicação em: 03/11/2020. 